\title{
Qualidade do leite ecológico produzido em uma unidade de produção do Rio Grande do Sul
}

\author{
Ecologic milk quality in a production unit of Rio Grande do Sul \\ Victoria Noel Vázquez Fernandez ${ }^{1}$, Maira Balbinotti Zanela², \\ Andrea Troller Pinto² \& Maria Edi Rocha Ribeiro ${ }^{3}$
}

\begin{abstract}
RESUMO
No Rio Grande do Sul, assim como no resto do país, a produção agrícola ecológica vem se tornando cada vez mais frequente, como resposta à demanda de mercado e à diversificação dos sistemas de produção. Com isso, cresce a necessidade de caracterização do produto a ser comercializado. Existem poucos relatos a respeito da composição química ou da contagem de células somáticas do leite obtido a partir desse tipo de sistema produtivo no estado. Com o objetivo de fazer uma caracterização inicial da qualidade do leite produzido num sistema de produção ecológico, que está em processo de credenciamento como orgânico, foi analisado o leite de uma pequena propriedade rural localizada no Vale dos Sinos, RS. Foram utilizadas quatro amostras do leite de mistura dos animais, coletadas no tanque de resfriamento, em diferentes dias, no mês de agosto de 2007. As amostras foram encaminhadas ao laboratório de análise de leite da Embrapa Clima Temperado, em Pelotas/RS, para determinação da composição química e contagem de células somáticas (CCS). A composição média encontrada foi: 3,14\% gordura, 3,19\% proteína bruta, 4,1\% lactose, $12,71 \%$ sólidos totais e 9,3\% sólidos desengordurados. A média da CCS foi 1,26 x $10^{6}$ cél $/ \mathrm{mL}$ de leite, ficando acima dos limites estabelecidos pela Instrução Normativa 51.
\end{abstract}

Descritores: composição química do leite, contagem de células somáticas, gordura do leite, lactose, leite orgânico, proteína bruta do leite.

\section{ABSTRACT}

Ecological production is coming more frequent in Rio Grande do Sul state, as in all Brazilian territory. It is a response for a growing market and production systems diversity. Because of these, standards must be defined to allow safe trade. There are few researches about milk composition and somatic cells count (SCC) in these system production in Rio Grande do Sul. This research aims to get information about composition and SCC, in milk produced in a ecological system. This property is being certified as an organic production system. The property is located at Vale dos Sinos. Four milk bulk samples were collected in August, 2007. The analyses were performed in Embrapa Clima Temperado, Pelotas/RS, to determinate composition and SCC. The compositions values (average) were: 3,14\% fat, 3,19\% protein, 4,1\% lactose, $12,71 \%$ total solids and $9,3 \%$ solids non fat. SCC average was $1,26 \times 10^{6} \mathrm{cel} / \mathrm{mL}$. This value does not agree with legal standards (IN51).

Keywords: lactose, milk composition, milk fat, milk protein, organic milk, somatic cels count.

${ }^{1}$ Programa de Pós-graduação em Ciências Veterinárias (PPGCV), Universidade Federal do Rio Grande do Sul (UFRGS), Porto Alegre, RS/Brasil. ${ }^{2}$ Departamento Medicina Veterinária Preventiva, Faculdade de Veterinária/UFRGS. ${ }^{3}$ Embrapa Clima Temperado, Pelotas, RS. CORRESPONDÊNCIA: M.B. Zanela [maira.zanela@ufrgs.br ; Fax: (51) 3308 7305]. 


\section{INTRODUÇÃO}

O sistema de produção orgânico visa à sustentabilidade socioambiental e econômica [7], com redução do uso de insumos externos e de aditivos químicos que possam deixar resíduos, valorizando a alimentação natural em harmonia com o meio ambiente [4].

No Brasil, a produção orgânica está regulamentada pela Lei $n^{\circ} 10.831$ [3] que objetiva a oferta de produtos saudáveis, de elevado valor nutricional, isentos de contaminantes que ponham em risco a saúde do consumidor, do agricultor e do meio ambiente. A legislação não estabelece padrões para a qualidade do leite produzido nesse sistema. No entanto, os parâmetros de qualidade do leite produzido e comercializado no país são definidos pela Instrução Normativa n51 (IN51) [2], servindo como indicativos para a produção orgânica.

O conceito de sistema orgânico de produção agropecuária e industrial abrange os denominados ecológico, biodinâmico, natural, agroecológicos etc. Entretanto, para usar a denominação 'orgânico' é necessário que o produtor tenha certificação emitida por entidade reconhecida pelo Ministério da Agricultura, Pecuária e Abastecimento (MAPA) [3]. Atualmente, não há no RS empresa do setor lácteo que possua o certificado de orgânico. No que se refere à produção leiteira ecológica, existem alguns produtores no RS, porém há poucos relatos a respeito da qualidade do leite oriundo destas propriedades. Apesar disso, os produtos ecológicos apresentam um crescimento elevado, em decorrência da grande aceitação de "produtos limpos" [4].

O objetivo deste trabalho é realizar a caracterização inicial da composição química e da contagem de células somáticas de leite produzido em uma propriedade que adota o sistema de produção ecológica no Vale do Rio dos Sinos/RS.

\section{MATERIAIS E MÉTODOS}

A propriedade leiteira estudada adota o sistema extensivo a pasto de produção ecológica e está localizada no Vale do Rio dos Sinos, no Rio Grande do Sul. Realiza o beneficiamento do leite, produzindo derivados lácteos para comercialização na região metropolitana de Porto Alegre. A unidade de produção de leite apresentava um rebanho com 14 fêmeas da raça Jersey, puros por cruza (PC), sendo 8 vacas em lactação e 6 vacas secas, no pré-parto. A idade média dos animais em produção era de 8,5 anos, enquanto a produção diária era de $14,6 \mathrm{~L} / \mathrm{vaca}$. A produção total era de aproximadamente 117 L/dia.

O manejo nutricional dos animais era realizado principalmente por pastejo de campo nativo e suplementação no cocho com cana-de-açúcar moída e capim-elefante, conforme disponibilidade da propriedade. Respeitando legislação nacional vigente [3] e diretrizes de órgãos certificadores [7], não era fornecido aos animais sal mineral ou substância tampão ruminal. Às vacas no pré-parto, era permitido apenas o pastejo de campo nativo. Os animais eram manejados em um único lote, independentemente do estágio produtivo em que se encontrassem. Nos meses de inverno, a oferta de pastagens era reduzida, por falta de planejamento forrageiro adequado.

As vacas eram ordenhadas duas vezes ao dia, utilizando ordenhadeira mecânica tipo balde ao pé, sendo o leite acondicionado em tachos metálicos e resfriado imediatamente em tanque de imersão, sendo mantido à temperatura média de $7^{\circ} \mathrm{C}$ até o momento em que era encaminhado à agroindústria.

A coleta das amostras de leite foi realizada no final do mês de agosto de 2007, em período pós-

Tabela 1. Composição química e contagem de células somáticas (CCS) do leite de uma propriedade com sistema de produção ecológico, do Vale do Rio dos Sinos, RS no mês de agosto de 2007.

\begin{tabular}{ccccccc}
\hline Amostra & $\begin{array}{c}\text { Gordura } \\
(\%)\end{array}$ & $\begin{array}{c}\text { Proteína } \\
\text { Bruta (\%) }\end{array}$ & $\begin{array}{c}\text { Lactose } \\
(\%)\end{array}$ & $\begin{array}{c}\text { Sólidos } \\
\text { Totais (\%) }\end{array}$ & $\begin{array}{c}\text { Sólidos } \\
\text { Deseng. (\%) }\end{array}$ & $\begin{array}{c}\text { CCS } \\
(\mathbf{x 1 0 0 0} \text { cels/ml) }\end{array}$ \\
\hline 1 & 3,11 & 3,14 & 4,19 & 12,72 & 9,61 & 716 \\
2 & 2,90 & 3,15 & 4,14 & 12,37 & 9,22 & 1.424 \\
3 & 3,64 & 3,23 & 3,96 & 13,32 & 9,09 & 1.949 \\
4 & 2,91 & 3,24 & 4,09 & 12,42 & 9,18 & 936 \\
\hline
\end{tabular}


estiagem na região, e quando se caracteriza a época de entressafra na produção leiteira. Foram coletadas quatro amostras do leite de mistura, após homogeneização, em diferentes dias. As amostras foram acondicio-nadas em frascos individuais contendo conservante, mantidas sob refrigeração e encaminhadas ao Laboratório de Qualidade de Leite da Embrapa Clima Tempe-rado, em Pelotas/RS. As amostras foram analisadas quanto aos teores de gordura, proteína bruta, lactose e sólidos totais, por radiação infravermelha, e à contagem de células somáticas, por citometria de fluxo.

\section{RESULTADOS}

Os resultados da composição do leite e da contagem de células somáticas estão dispostos na Tabela 1. Os valores médios de composição do leite das amostras realizadas foram: $3,14 \%$ de gordura, $3,19 \%$ de proteína bruta, $4,1 \%$ de lactose, $12,71 \%$ de sólidos totais e 9,3\% de sólidos desengordurados. A média da contagem de células somáticas foi de 1,26 x $10^{6} \mathrm{cel} / \mathrm{mL}$ de leite.

\section{DISCUSSÃO}

Atualmente, no Brasil, a produção de leite em sistemas ecológicos e/ou orgânicos está crescendo, como resposta ao incentivo de diversos setores da sociedade e impulsionada pelo mercado externo. Ainda assim, são poucas as empresas que possuem certificação. Há algumas propriedades localizadas no centro-oeste, sudeste e nordeste do Brasil que têm certificação de diferentes órgãos, mas ainda existem poucos dados sobre a qualidade do leite produzido por essas propriedades.

A produção de alimentos orgânicos está regulamentada dentro do território nacional, por disposição do MAPA, desde 1999, através da IN7 de maio do mesmo ano [1] e pela Lei 10.831, de dezembro de 2003 [3]. Entretanto, não existem padrões estabelecidos para a qualidade dessa matéria prima. A IN51, de setembro de 2002 do MAPA, estabelece os padrões do leite produzido e comercializado sob Inspeção Federal [2], independentemente do sistema produtivo adotado, e estes foram usados para comparação da qualidade do leite da propriedade estudada.

A IN51 aprova os regulamentos técnicos de produção, identidade e qualidade do leite cru refrigerado produzido no Brasil. Os limites estabelecidos por esta para composição química do leite são: gordura - mínimo 3,0\%, proteína bruta - mínimo 2,9\% e sólidos desengordurados - mínimo 8,4\%. Os limites máximos para CCS, vigentes para as Regiões Sul, Sudeste e Centro-Oeste do Brasil, de julho de 2005 a julho de 2008, eram $1,0 \times 10^{6}$ células $/ \mathrm{mL}$ de leite, e de julho de 2008 a julho de 2010 é de 7,5 x $10^{5}$ células $/ \mathrm{ml}$.

As amostras de leite da propriedade estudada apresentaram teores de proteína bruta e sólidos desengordurados acima dos limites mínimos estabelecidos pela IN51 (Tabela 1), estando, portanto, de acordo com a legislação vigente. Com relação aos teores de gordura, dois valores foram inferiores ao limite mínimo estabelecido.

Para a CCS, a média e dois valores ficaram acima do limite máximo estabelecido inicialmente pela IN51 e apenas uma amostra apresentou valor abaixo do limite máximo estabelecido atualmente $\left(7,5 \times 10^{5}\right.$ células $\left./ \mathrm{ml}\right)$.

Os resultados médios de composição do leite foram inferiores aos encontrados para o leite de vacas Jersey em experimento realizado na Argentina, onde os animais foram mantidos sob condição experimental de pastoreio e com manejo nutricional adequado em períodos invernais [5]. No experimento realizado na Argentina, os valores médios encontrados foram: 5,0\% de gordura, 3,86\% proteína bruta, 5,0\% de lactose e $9,44 \%$ de sólidos desengordurados.

Em outro experimento, realizado no Rio Grande do Sul, foi observado teor de gordura $4,10 \%$, proteína bruta $3,42 \%, 4,4 \%$ de lactose, $12,76 \%$ de sólidos totais (ST) e 8,66\% de sólidos desengordurados para animais Jersey, valores também superiores aos encontrados neste trabalho [12].

Estudos realizados na Suécia demonstram não haver correlação com o sistema de produção orgânico [11] e diferenças na composição do leite, já que a composição do leite orgânico analisado naquele país não demonstrou diferença significativa daquele obtido em sistemas produtivos considerados convencionais, tanto para parâmetros químicos como para CCS. Entretanto, segundo esses autores, [11] as médias encontradas para CCS em ambos os sistemas ficaram entre $1,74 \times 10^{5}$ e $2,05 \times 10^{6} \mathrm{cel} / \mathrm{ml}$, valores bem abaixo dos encontrados neste trabalho.

A composição do leite é afetada por fatores tanto nutricionais como não nutricionais, dentre os quais está a alta CCS [8]. Altas contagens celulares no leite decorrem, muitas vezes, de situações deficientes no manejo de ordenha e saúde do úbere. Podem também estar relacionadas à fase de lactação e idade do animal 
$[8,10]$. Quadros de mastite, muitas vezes, mantêm o teor de proteína bruta do leite inalterado, porém há aumento das proteínas do soro e redução da caseína $[6,8,10]$. Observa-se ainda redução no teor de lactose e gordura, aumento na CCS e alteração na concentração de sais minerais presentes no leite $[6,10]$.

Nesta situação específica, é provável que as alterações na composição do leite sejam decorrentes do somatório de fatores, tais como nutrição inadequada, manejo de ordenha deficiente etc. Os resultados deste relato sugerem tanto desequilíbrio nutricional do rebanho, com possível subnutrição, como deficiência no manejo de ordenha e comprometimento da saúde da glândula mamária dos animais. Espera-se que o presente relato traga incentivo à especialização da produção leiteira no Brasil, também no que concerne à produção orgânica ou ecológica, resultando em melhoria na qualidade do produto que é ofertado à população.

\section{REFERÊNCIAS}

1 BRASIL. Ministério da Agricultura, Pecuária e Abastecimento. 1999. Instrução Normativa no . 7, de 17 de maio de 1999. Estabelece as normas de produção, tipificação, processamento, envase, distribuição, identificação e de certificação da qualidade para os produtos orgânicos de origem vegetal e animal. Disponível em: <http://extranet.agricultura.gov.br/ sislegis-consulta/consultarLegislacao>. Acessado em 10/2007.

2 BRASIL. Ministério da Agricultura, Pecuária e Abastecimento. 2002. Instrução Normativa n ${ }^{\circ}$. 51 , de 18 de setembro de 2002. Aprova os Regulamentos Técnicos de Produção, Identidade e Qualidade do Leite tipo A, do Leite tipo B, do Leite tipo C, do Leite Pasteurizado e do Leite Cru Refrigerado e o Regulamento Técnico da Coleta de Leite Cru Refrigerado e seu Transporte a Granel. Disponível em: 〈http://extranet.agricultura.gov.br/sislegis-consulta/consultarLegislacao〉. Acessado em 10/2007.

3 BRASIL. Ministério da Agricultura, Pecuária e Abastecimento. 2003. Lei 10.831, de 23 de dezembro de 2003. Dispõem sobre a agricultura orgânica e dá outras providências. Disponível em: <http://extranet.agricultura.gov.br/sislegis-consulta/consultarLegislacao>. Acessado em 10/2007.

4 Fagundes V. 2004. Leite Orgânico: pesquisas orientam a produção, que ganha adeptos e promete aumentar os lucros no campo. Revista Minas na Ciência. 20. Disponível em: 〈http://revista.fapemig.br/materia.php?id=205>. Acessado em 10/2007.

5 Comerón E., Romero L., Cuatrín A. \& Maciel M. 2005. El efecto racial o genético. In: Taverna M. (Ed.) Manual de referencias técnicas para el logro de leche de calidad. 2.ed. Rafaela: INTA, pp.119-134.

6 Furtado M.M. 1991. A qualidade do leite. In: A Arte e a Ciência do Queijo. 2.ed. São Paulo: Ed. Globo, pp.30-31.

7 Instituto Biodinâmico. 2006. Diretrizes para o padrão de qualidade 'Orgânico Instituto Biodinâmico'. 13.ed. Disponível em: 〈www.ibd.com.br>. Acessado em 10/2007.

8 Instituto Nacional de Tecnología Agropecuaria (INTA). 1996. Gacetilla Informativa ${ }^{\circ}$ 5: Estratégias de manejo nutricional para mejorar la proteína em leche. Rafaela: INTA.

9 Organización de las Naciones Unidas para la Agricultura y Alimentación (FAO/OMS). 2006. Directrices para la producción, elaboración, etiquetado y comercialización de alimentos producidos orgánicamente. Disponível em: <http:/ /www.codexalimentarius.net>. Acessado em 10/2007.

10 Mahieu H. 1991. Factores que influyen en la composición de la leche. In: Luquet F.M. \& Bonjean-Linczowski Y. (Eds.) Leche y Productos Lacteos 1: La leche. Zaragoza: Editorial Acribia S.A., pp. 117-140.

11 Toledo P., Andren A. \& Björck L. 2002. Composition of raw milk from sustainable production systems. International Dairy Journal. 12: 75-80.

12 Zanela M.B., Fischer V., Ribeiro M.E.R., Stumpf Jr. W., Zanela C., Marques L.T. \& Martins P.R.G. 2006. Qualidade do leite em sistemas de produção na região Sul do Rio Grande do Sul. Pesquisa Agropecuária Brasileira. 41: 153-159.

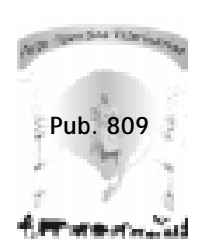

